\title{
ABSTRACTS
}

[This section of the ANNALs is published in collaboration with the two abstracting Journals, Abstracts of World Medicine, and Abstracts of World Surgery, Obstetrics and Gynaecology, published by the British Medical Association. The abstracts are divided into the following sections: acute rheumatism; articular rheumatism (rheumatoid arthritis, osteo-arthritis, spondylitis, miscellaneous); gout; non-articular rheumatism; general articles. After each subsection of abstracts follows a list of articles that have been noted but not abstracted. Not all sections may be represented in any one issue.]

\section{Acute Rheumatism}

Some Public Health Aspects of Rheumatic Fever. WheATLEY, G. M. (1947). W. Va. med. J., 43, 57.

The last ten years have been important in the control of rheumatic fever, chiefly because: (1) the war has helped greatly in understanding its epidemiology; (2) more doctors have become aware of the need to apply this knowledge; (3) (in America) the American Rheumatic Fever Council has been a spearhead in the attack.

The success or failure of control efforts must be judged partly by recurrence rates, and Wilson and Lubschez (J. Amer. med. Ass., 1944, 126, 477) found that the chance of a major recurrence was two to three times as great in the year following the attack as in one, two, or more years after; also that age was important in assessing the likelihood of a recurrence ( $25 \%$ chance with children aged 4 to $13,8.6 \%$ when aged 14 to 16 , and only $4 \%$ when aged 17 to 25). Family susceptibility plays a part; but why must a child reach school age before he acquires the disease in recognizable form, and why does not the child of school age bring it back to the pre-school child at home? Other factors are geographical and seasonal variation; in three areas of America the incidence is very high (Rocky Mountain states, Great Lakes region, and middle Atlantic states), in southern California and the middle west very low. There is also the seasonal variation, highest incidence in April, lowest in November. Also must be mentioned the steady decline in mortality from rheumatic fever and rheumatic heart disease in children since 1910.

No way is known of preventing the initial attack. Methods tried in the past to prevent recurrences include transfer to a warmer climate, improving the diet, removal of tonsils, and the prophylactic use of drugs such as salicylates and sulphonamides. None of these has a specific effect. With sulphonamide prophylaxis, out of six groups the recurrence rate in those treated was only $2.3 \%$ with no deaths, in the controls $22.6 \%$ with six deaths. But there is the danger of producing sulphonamide-resistant strains of the streptococcus. Salicylate therapy has not been convincing, and tonsillectomy should be carried out only for normal reasons. Methods of dust control by penicillin, ultra-violet light, etc., have also been tried.

The complex nature of the disease produces certain - problems which cannot be solved by the practising physician alone; he needs to be able to make use of a consultant when necessary, and also to be able to recommend his worst crippled patients for occupational therapy. Convalescence is often prolonged and expensive, and the community should play a part in easing the financial burden. In the U.S.A. a start has been made, since 1939, by the Children's Bureau, and since February, 1944, by the Council on Rheumatic Fever of the American Heart Association. In one State and a few of the largest cities campaigns have been started to educate people in the subject of rheumatic fever; but it is admitted that none of the schemes are as well co-ordinated as the London County Council's scheme of 1927, although some of the cities (for example, Syracuse, N.Y.) have based their programmes on the ideas of the L.C.C. Statistics since 1927 show that all the money and hard work spent on the scheme have been worth while; for whereas $2 \%$ of the school children of London in 1926 suffered from acquired heart disease, the figure had fallen by 1936 to $0.8 \%$. T. G. C. Early.

Rheumatic Heart Disease in the Adult. Eggleston, $\mathbf{C}$. (1947). Amer. J. Med., 2, 278.

The author is not convinced of the relationship between haemolytic streptococcal infection of the upper respiratory tract and the reactivation of the rheumatic process in the susceptible individual, nor of the value of sulphonamide prophylaxis. The clinical manifestations of the disease are more important than laboratory tests both in diagnosis and in deciding when active rheumatic disease has ceased. In the active phase adequate care will minimize cardiac damage, which in the polycyclic type may affect the heart muscle more than the valves. A positive throat culture does not necessarily signify rheumatic activity.

Rheumatic heart disease in the adult may be classified into four categories: (1) active rheumatic fever with evidence of carditis, endocarditis, or pericarditis; (2) cases showing physical signs of valvular disease but no evidence of present activity; (3) active rheumatic fever with residual valvular disease; (4) bacterial endocarditis. Active rheumatic carditis is probably as common in the adult as in the child, and the author maintains that serial sections of the heart from autopsies on the rheumatic adult would show histological evidence of rheumatic activity in a great majority of cases. Mitral stenosis is of no prognostic value except that a first appearance in adult life is less serious than a childhood affection. Auricular fibrillation may be transient or permanent, and, if congestive heart failure supervenes, control is more readily affected when auricular fibrillation is present than when the pulse is regular. Rheumatic pericarditis is not of such serious prognostic significance as it was formerly 
considered to be. The diagnosis of early bacterial endocarditis may be difficult, and recurring pulmonary infarction is a clinical manifestation not ordinarily emphasized. There is no advantage in giving salicylates intravenously rather than orally. Convalescence should not be hastened, and later the general physical health should be maintained as high as possible while patients should be allowed to be as active as they are able. If pregnancy occurs, it should be interrupted only if there is evidence of heart failure, and labour should be made as easy as possible. Active rheumatic carditis is a valid reason for terminating pregnancy.

T. G. Reah.

The Electrocardiogram in the Diagnosis and Management of Rheumatic Fever. SoKolow, M. (1947). Calif. Med., 66, 221.

The diagnosis of rheumatic fever in adults is sometimes difficult, particularly where there is no previous history, no cardiac enlargement, and no diastolic murmurs. In some instances the electrocardiograph may reveal significant changes. In a series of 700 cases reported in this paper, electrocardiographic abnormalities were found in 144, the most important being A-V block in 86 and $T$-wave changes in 52. The diagnosis of $A-V$ block was made when P-R interval was over 0.20 seconds or if with clinical improvement a decrease in at least 0.04 seconds occurred. These changes may be surprisingly transient and intermittent, and the frequency of abnormal tracings depends on the frequency with which E.C.G.s are taken. T-wave changes are best shown by serial records, progressive changes towards normal through diphasic, flat, and low $\mathrm{T}$-wave stages being found. Lead 4 may be the only one to show changes.

In addition to being valuable in diagnosis, electrocardiography is useful in following the course of rheumatic fever, particularly in the polycylic forms, many of which ate sub-clinical; in such cases the reappearance of abnormalities in the E.C.G. may be the only objective sign of recrudescence.

H. A. Burt.

The Action of Salicylates in Rheumatic Fever. GlazEBROOK, A. J., and CoOKSON, B. (1947). Edinb. med. J., 54, 193.

The authors describe Maclagan's first use of salicin in the treatment of acute rheumatism and point out that he recognized that it was not likely to benefit the carditis. They describe a series of 103 patients suffering from rheumatic fever who had been treated with anti-streptococcal serum or with human convalescent serum and not with salicylate, in which the incidence of carditis was no higher than in comparable groups treated with salicylate.

They recall Coburn's claim that a plasma salicylate concentration of $36 \mathrm{mg}$. per cent. would prevent carditis, and that to maintain this level intravenous administration of salicylate was indicated. But other workers had not been able to confirm these claims. Taran and Jacobs, while unable to agree with him on the prevention of carditis, agreed that his high plasma salicylate was desirable, and in 18 children whom they treated with salicylate by mouth found toxic symptoms manifested as tachypnoea in only 1 . Other workers found a varying incidence of toxic symptoms, the incidence of which was always higher in patients to whom the drug was given intravenously, and "opinions seem to be hardening against the intravenous method of treatment". Sufficiently high plasma salicylate concentrations can be obtained by oral administration.
The authors discuss the role of bicarbonate, which is traditionally given with salicylate. Some say that it prevents a fall in alkali reserve, others that the salicyl radical specifically stimulates the respiratory centre and, by causing a loss of carbon dioxide by hyperpnoea, raises the alkali level of the blood which causes the excretion of alkaline urine and therapy a secondary loss of fixed alkali. These authors suggest that both these mechanisms may play their part, and agree with others that bicarbonate alleviates the dyspnoea of salicylism by depressing the blood salicylate level; while a daily dose of $8 \mathrm{~g}$. of sodium salicylate will achieve a plasma salicylate level of $36 \mathrm{mg}$. per cent. in an adult, $12 \mathrm{~g}$. of salicylate will be needed to achieve this level if it is given with an equal dose of bicarbonate. They suggest that salicylate should initially be given without bicarbonate, and that the latter should be given later if symptoms of salicylism occur. They note the work of Dry, Butt, and Scheifley, which showed that para-amino benzoic acid if given with salicylate and bicarbonate raises the blood salicylate level.

The possibility that salicylate may lower the blood prothrombin level and exert an anti-coagulant effect has been the subject of conflicting reports. There is evidence that a pre-existing ascorbic acid deficiency may predispose to a fall in prothrombin index when salicylate is administered. In a controlled series of patients suffering from rheumatic fever and treated with salicylate and bicarbonate, the authors found that while the administration of salicylate did cause a fall in prothrombin level in both rheumatic and non-rheumatic subjects, it was moderate only. Vitamin $\mathbf{K}$ raised the prothrombin index of salicylate-treated normals in all but one of series of 7. The authors note that while much work on this subject was stimulated by Link's suggestion that dicoumarin was degraded by the body into salicylate, this suggestion is not securely founded.

All 20 patients in their series noticed symptoms of salicylism, and 2 were so severely affected that administration of the drug had to be stopped. In the rest the salicylate discomfort was greater initially and rapidly improved.

It may be that salicylate antagonizes a product such as pantothenate which is known to be produced by certain bacteria. Recently Guerra has shown that in rheumatic conditions the hyaluronic acid of the connective tissue is damaged by a hyaluronidase, and suggests that salicylate acts by inhibiting this enzyme. Coburn and Kapp suggest that salicylate inhibits the antigen-antibody reaction which they claim to be disordered in rheumatic fever. The authors speculate on the possibility that the effect of salicylate is to prevent the internal clotting of cells brought about by an antigen-antibody reaction which may have an irritant effect. They recall experiments which have demonstrated the anti-anaphylactic properties of heparin, and do not think that " its appearance in the blood during anaphylactic shock can be dismissed as an unimportant side effect". There is experimental evidence that histamine or a substance like it may be produced by anaphylactically reacting cells and that this production of histamine can be inhibited by adequate amounts of heparin. They speculate further on the relationship between the highly accelerated ascorbic acid utilization in rheumatic fever and the possible part played by ascorbic acid in tissue respiration. Finally they suggest a correlation between the known'beneficial effect of jaundice in severe chronic rheumatism and the reduction in the coagulability of the blood known to occur when bile is present in the blood stream.

W. Tegner. 
Prophylactic Sulphanilamide in Rheumatic Fever: PreHiminary Report. STOKes, H. L. (1947). Proc. $R$. Aust., Coll. Phys., $2,16$.

The author presents the results to date of sulphanilamide prophylaxis in convalescent and quiescent cases of rheumatic fever. His experience extends over 2 years, during which time sulphanilamide was given to 238 children in doses ranging from $0.5 \mathrm{~g}$. per day to $0.5 \mathrm{~g}$. three times a day. Toxicity was not found to be a serious limiting factor. Close co-operation was maintained with the bacteriological department, and throat swabs and typing were studied in a high proportion of cases. There was no significant decrease in carrier rates of haemolytic streptococci in the treated as opposed to the control group, although there appeared to be a decrease in the number of clinical relapses in the control group. Furthermore the percentage of organisms resistant to sulphanilamide rose significantly in the treated series, from $7 \cdot 1$ to $31 \%$.

The author comments on these interesting findings, and refers to the experience of American workers in the same field, who found that the induction of drug resistance was a definite danger. It is suggested that prophylactic use of sulphanilamide may be unwarranted, or even dangerous, though as yet there is no proof that the drug-resistant organisms isolated were in fact of the same type as those found in throat swabs before drug therapy.

[The author is continuing this survey; further figures and bacteriology should prove of value.]

David P. Nicholson.

Penicillin Prophylaxis in Acute Rheumatism. BURKE, P. J. (1947). Lancet, 1, 255.

Penicillin by mouth is suggested as an alternative to sulphonamides in the prophylaxis of acute rheumatism. [No reference is made to any clinical observations for nicotinamide deficiency in the treated patients.]

T. G. Reah.

The Differential Diagnosis of Adult Rheumatic Fever and Rheumatoid Arthritis. ENGLEMAN, E. P. (1947). Calif. Med., 66, 277.

The differential diagnosis of acute rheumatoid arthritis occurring in young adult males and adult rheumatic fever occurring without a previous history of acute rheumatism and without signs of cardiac involvement may be exceedingly difficult. In this paper " the most helpful differential diagnostic features" are outlined, the most significant being (1) the presence or absence of residual changes in the joint, and (2) the response to salicylates. In rheumatic fever residual changes almost never occur, whereas in rheumatoid arthritis they are the rule. Salicylates have little effect with rheumatoid. arthritis; in rheumatic fever objective signs such as effusion invariably clear up with salicylates, though they may take 18 days to do so. It is emphasized that rheumatic fever patients frequently continue to experience joint pain for several months in spite of adequate salicylates though physical signs in the joints themselves are absent.

H. A. Burt.

Laboratory and Clinical Criteria of Rheumatic Carditis in Children. TARAN, L. M. (1947). N. Y. St. J. Med., 47, 703 .
Some Observations on the Prevalence of Rheumatic Heart Disease in Canada. Kerrh, J. D., and PequzGnat, L. A. (1947). Can. J. publ. Hlth., 38, 111.

Acute Abdominal Appearances in Rheumatic Fever. (Cuadros agudos de vientre en la fiebre reumatica.) Piaggio blanco, R. A., Dubourditu, J., and CasaMAYOU, E. (1947). Rev. argent. Reumatol., 12, 4.

Rheumatic Brain Disease: Late Sequel of Rheumatic Fever. BRUETSCH, W. L. (1947). J. Amer. med. Ass., 134, 450.

Rheumatic Fever. (A rheumés lázrói.) Kelemen, E. (1947). Orvostud. Beszám., 1, 475.

\section{Articular Rheumatism}

(Rheumatoid Arthritis)

Studies of the Peripheral Circulation in Rheumatoid Arthritis. [In English.] RourTI, O. (1947). Ann. Med. intern. fenn., 36, 158.

The author reviews the literature on the peripheral circulation in rheumatoid arthritis and concludes that circulatory disturbances are not now regarded as an aetiological factor: He describes his air plethysmograph and the methods he used to study the circulation in the forearms and hands of patients suffering from rheumatoid arthritis and of controls. He found wide variation in the circulation of normal controls, for "the maximum circulation of the healthy test subjects was in fact 5 times greater than the minimum ". In rheumatoid arthritis when there was no active inflammation the circulation was similar to that of normals. This was surprising in view of the fact that there is agreement that capillary microscopy reveals a diminution in the peripheral circulation of such patients. Where there was inflammation of the hands the circulation was increased above that of normals.

The author discusses his methods and possible criticisms of his technique. He concludes that his findings, although apparently not in agreement with the finding by capillary microscopy that the circulation in the nail bed is retarded, may mean that while circulation in the nail bed and skin is slowed down, in the limb as a whole it is unaffected. W. S. Tegner.

Investigations of the Cerebrospinal Fluid in Cases of Rheumatoid Arthritis. SUNDELIN, F. (1947). Amer. J. Med., 2, 579.

The author points out that the symptomatology of rheumatoid arthritis includes a number of neurological symptoms which indicate involvement of the central and autonomic nervous system. Such symptoms include: (1) muscle atrophy, (2) paresis, (3) tremor of the fingers and hands, (4) trophic (autonomic) disturbances.

The author studied 141 cases ( 38 male, 103 female); 58 (41\%) had spinal-fluid protein values (Izikowitz method) which were pathological in one way or another, and a total of $66(46.8 \%)$ had fluids which were in some way changed pathologically. The mean value of the total protein of the spinal fluid in normal women was taken as $31 \mathrm{mg}$. per $100 \mathrm{ml}$., and the maximum "permissible" statistically calculated normal value as $48.7 \mathrm{mg}$. per $100 \mathrm{ml}$. 
The protein was above normal limits in 6 cases, all in women, the values varying between 51 and $67 \mathrm{mg}$. per $100 \mathrm{ml}$. The globulin content exceeded normal limits in 17 cases, the normal mean value being accepted as $7.7 \mathrm{mg}$. per $100 \mathrm{ml}$. and the maximum "permissible" value as $13.7 \mathrm{mg}$. per $100 \mathrm{ml}$. for men, with values of 6 and 10.7 $\mathrm{mg}$. per $100 \mathrm{ml}$. for women. The values for men varied between 14 and $21 \mathrm{mg}$. per $100 \mathrm{ml}$., and for women between 11 and $28 \mathrm{mg}$. per $100 \mathrm{ml}$. The albumin content was increased in 6 cases, all in women, and varied between 38.9 and $46.2 \mathrm{mg}$. per $100 \mathrm{ml}$. (normal mean value $22 \cdot 9$, and maximum " permissible" value $38.4 \mathrm{mg}$. per $100 \mathrm{ml}$.). The globulin-albumin quotient was abnormally high in 52 cases ( 14 men, 38 women). The author states that if a comparison is made between the total protein values obtained and the normal values found in large series no considerable difference appears, but the globulin-albumin ratio is considerably altered, the mean value being 0.36 as compared with a normal value of 0.25 .

As the colloidal gold reaction is conditioned by the $\mathbf{J}$-globulin, the gold-sol reaction was investigated in 107 cases; 15 reactions were pathological. Neither the degree of severity of the disease nor the duration of illness appeared to affect the protein values. Seven cases had an increased spinal-fluid cell count. All the patients with a pathologically increased protein content, except 1 , exhibited one or more neurological symptoms.

\section{S. Oram.}

Serum Lysolecithin in Rheumatoid Arthritis, Pregnancy, and Jaundice and in Normal Persons. KuZELL, W. C., and Davison, R. A. (1946). J. Lab. clin. Med., 31, 1223.

An investigation was undertaken to discover whether the remissions in rheumatoid arthritis which are known to accompany pregnancy and jaundice were associated with any change in the serum lysolecithin level. It was found that the mean values were the same in normal controls, rheumatoid arthritis, pregnancy, and jaundice. No relationship between the lysolecithin values and the erythrocyte sedimentation rate could be demonstrated. R. Bodley Scott.

Rheumatoid Arthritis: V. The Agglutination of Hemolytic Streptococci. Wallis, A. D. (1947). Amer. J. med. Sci., 213, 94.

Relatively feeble agglutinins for the group A streptococcus have been found to occur in the sera of normal individuals. The author thinks the increased ability of the sera of patients with typical rheumatoid arthritis to agglutinate selected strains of group A streptococcus is due to the non-specific enhancement of these antibodies. This property of the serum is apparently related to the ability to agglutinate suspensions of fine collodion particles.

T. D. M. Martin.

Prolonged Administration of Sulfonamides in Rheumatoid Arthritis. [In English.] VIRKKUNEN, M. (1947). Ann. Med. intern. fenn., 36, 198.

Rheumatoid arthritis was treated in 38 cases with various sulphonamide drugs for long periods. There was improvement in all but 6 cases. Sensitivity reactions caused by the sulphonamides produced a sharp and definite therapeutic effect. After treatment was stopped 15 cases were studied for 2 months, and the condition of only 3 remained good.

A. Kekwick.
Blood Transfusion in the Treatment of Rheumatoid Arthritis. APPleQvist, O., and Holsti, O. (1947). Schweitz. med. Wschr., 37, 977.

Twenty-four mostly severe cases of rheumatoid arthritis, 15 women and 9 men, were treated with from 2 to 13 weekly blood transfusions in addition to "a certain basic treatment". The impression was in most cases favourable and confirmed scanty earlier experience although dramatic improvements were rare. The authors think that blood transfusion might well be given (in preference to and before resorting to gold therapy) a fair trial in the form of a long series. They suggest that the most suitable patients would be young and anaemic ones in an early stage of the disease. Further studies are being made.

From the Author's summary.

On the Occurrence of Keratoconjunctivitis Sicca in Cases of Rheumatoid Arthritis. [In English.] STENSTAM, T. (1947). Acta med. Scand., 127, 130.

The earlier work of Sjögren the syndrome of keratoconjunctivitis sicca with arthritis is referred to. The symptoms are smarting pain and a gritty feeling in the eyes, and reduced tear secretion. The conjunctiva stains strongly with bengal rose. Dryness of the nose and pharynx may occur, and $80 \%$ of patients also suffer from chronic arthritis. Sjögren regarded the syndrome as a distinct disease.

The author draws his material largely from the rheumatological clinic at Lund Hospital, Sweden. $\mathrm{He}$ finds that $10.5 \%$ of cases of chronic rheumatoid arthritis have typical keratoconjunctivitis sicca. H.F. Turner.

Arthritis Mutilans [In English]. NiELSEN, B., and SnORRASON, E. (1946). Acta radiol., Stock., 27, 607.

Three cases of arthritis mutilans in patients with longstanding polyarthritis are reported. In all, the destructive process was confined to the metacarpophalangeal and proximal interphalangeal joints; there were no destructive changes in the distal interphalangeal joints. This disease is found predominantly in females. Its onset is apparently insidious, though no patients have been followed up and radiographed over a long enough period to be certain of this. Apart from the destructive changes localized to certain joints, there appears to be no feature to distinguish the condition from ordinary polyarthritis. Histologically, fatty degeneration is sometimes seen in the bones. This is not found in chronic polyarthritis, but the author considers that it is probably a secondary change due to disuse resulting from the increased degree of immobility following on the destructive changes. Vascular changes are minimal and there is no evidence of nerve degeneration. It is considered that arthritis mutilans (main en lorgnette syndrome) exists as aseparate entity, but that there is no sharp dividing-line between mutilating and non-mutilating varieties of chronic polyarthritis.

P. Kerley.

Contribution to the Study of Variations in Fibrinogen Levels in Progressive Chronic Polyarthritis. (Contribution a l'étude des variations du taux fibrinogène dans la polyarthrite chronique évolutive.) COLINET, E. (1947). Arch. Rheum., 7, 72.

The fibrinogen content of the plasma in cases of chronic progressive polyarthritis is determined, and a relation established between fibrinogen level and erythrocyte sedimentation rate. If the fibrinogen values are plotted as abscissae and the corresponding erythrocyte 
sedimentation rates as ordinates, a curve results with the form of a hyperbola. The fibrinogen value, that is, rises more slowly with increase in the E.S.R. It reaches a maximum value of about $6 \mathrm{mg}$. per $\mathrm{ml}$. of plasma; this corresponds to an E.S.R. of 60 to $70 \mathrm{~mm}$. in 2 hours by the Westergren method. The value does not increase further with increase in the E.S.R. With clinical improvement the fibrinogen value returns very slowly towards the normal, but it is rare to find complete return to a normal figure. Kenneth Stone.

Disturbance of Glucose Metabolism in Progressive Chronic Polyarthritis. (Troubles du métabolisme glucidique au cours de la polyarthrite chronique évolutive.) Polonovski, M., Coste, F., and DelbarRe F. (1947). Bull. Soc. méd. Hôp. Paris, 63, 489.

Glucose-tolerance tests were performed on 16 patients suffering from progressive chronic polyarthritis; $50 \mathrm{~g}$. glucose was given by mouth and the blood sugar observed for 3 hours subsequently. The authors conclude that in this condition there is a disturbance of glucose metabolism for which there is no explanation.

T. G. Reah.

Penicillin in the Treatment of Keratosis Blennorrhagica with Polyarthritis. Freireich, A. W., Schwartz, S., and Steinbrocker, O. (1947). Arch. intern. Med., 79, 239.

Keratosis blennorrhagica with polyarthritis is a rare condition occurring about once in every 5,000 cases of gonorrhoea. The symptoms are urethritis, arthritis, and dermatosis. Chills and fever accompany the malady, which follows chronic or relapsing gonorrhoea. The urethritis is typical of a chronic insufficiently treated gonorrhoeal infection. The arthritis is usually widespread, variable, and polyarticular, and the lesions of the skin consist of vesicles, pustules, and crusts with widespread thickening and desquamation of the skin. The crusts may pile up under the nails and separate them from their beds. Diffuse osteoporosis can sometimes be detected, especially in the wrists; and occasionally proliferative change in the periosteum of the manubriosternal articulation. The present series consists of three cases, two of which were cured with penicillin; the third patient came too late for treatment and died.

$$
\text { G. F. Walker. }
$$

Three Cases of the Felty Syndrome. [In English.] YTREHUS, O. (1947). Acta med. Scand., 126, 437:

The syndrome described by Felty in 1924 (of chronic polyarthritis, splenomegaly, and leucopenia) appears to -have evoked little comment in the English literature, though a number of cases have been reported from Europe, Scandinavia, and America. Ytrehus reports three further cases in women aged 38, 57, and 60 years with polyarthritis of 13 to 19 years' duration who on repeated examination showed splenomegaly and leucopenia, with granulopenia and preponderance of young forms. One patient died, apparently of generalized sepsis, but autopsy revealed no distinctive pathological or histological features.

Splenectomy was not performed in any of these cases, though one patient had a sister who had been treated by splenectomy for the same syndrome (result not stated). Several surgeons have reported good results on marrow function and articular symptoms following removal of the spleen in cases of the Felty syndrome, and this would seem to be a justification for its recognition. However, the results as published were not invariably as strikingly good, and there is, so far, no reason to ascribe the syndrome to any definite causative agent. The granulocytopenia may be due to an alteration in splenic function or to a toxic effect on the bone marrow analogous to that which produces the arthritis.

M. Baker.

On So-called Allergic Arthritis Symptoms. [In English.] Applegreen, A. (1947). Ann. Med. intern. fenn., 36, 5 .

A Practical Hypothesis for Chrysotherapy. CoKE, $\mathbf{H}$. (1947). Rheumatism, 3, 126.

Physical Medicine in the Care of Rheumatoid Arthritis. Polley, H. F. (1947). Sth. med. J., 40, 596.

\section{(Osteo-arthritis)}

A Contribution to the Surgical Treatment of Osteoarthritis of the Hip-joint. A Clinical Study. [In English.] GADE, H. G. (1947). Acta chir. Scand., 95, Suppl. 120.

The author performed 130 operations between 1938 and 1946 on a series of 115 patients with osteo-arthritis of the hip-joint. Three patients died, of pulmonary embolism, fat embolism, and paralytic ileus respectively.

The object of the monograph is to make a comparative evaluation of the various operative methods employed, and to describe the indications for them. The role of the joint capsule in the symptomatology of osteo-arthritis and the therapeutic value of joint-capsule extirpation in the operative treatment are dealt with. There is a chapter describing the methods of examination and the manner in which the clinical findings were recorded, including a new procedure for the registration of the functional value of mobility in the hip-joint. A detailed account is given of the therapeutic results obtained, and postoperative complications are discussed. In his last chapter the author makes a comparative evaluation of arthrodesis and arthroplasty on the basis of his own experience, and gives his view on the indications for these two types of operation.

The monograph is unsuitable for abstracting, and should be read in full by those interested. It is illustrated with radiographs, and case reports are presented in detail. There is a comprehensive bibliography.

Arthrodesis of the Hip by a Screw. (L'arthrodèse de la hanche par vissage.) Casuccio, C. (1947). Rev. Orthopéd., 33, 78.

The standard operation at present recommended for arthrodesis of the hip consists of a simple "blind" transarticular insertion of the screw without exposure of the hip-joint, followed if necessary by a subtrochanteric osteotomy to correct any deformity. The "blind" operation has now been performed 25 times for uncomplicated osteo-arthritis and 4 times for osteo-arthritis associated with unreduced congenital dislocations. In addition there have been 10 cases in which screwing has been used as part of an intra-articular arthrodesis and in which rapid and satisfactory bony fusion was obtained. Of the 25 patients submitted to arthrodesis by means of a screw alone, 18 have been followed up for more than 
6 months. The other 7 are too recent. Of the 18 joints, 16 have a solid ankylosis, 12 of them being ankylosed in good position, and 4 are somewhat flexed and adducted. In 12 cases bony fusion of the hip appears to have occurred.

\section{(Spondylitis)}

Excretion of 17-Ketosteroids in Ankylosing Spondylarthritis and in Rheumatoid Arthritis: A Preliminary Report. Davison, R. A., Koets, P., and Kuzell, W. C. (1947). J. clin. Endocrinol., 7, 201.

An investigation of the 17-ketosteroid output in the urine of patients with ankylosing spondylitis is described. In 13 male patients an average excretion of $27.3 \mathrm{mg}$. in 24 hours was found, with a range of from $19 \cdot 2$ to 43.7 . The average value is somewhat high for the group (the average for normal males is $14 \mathrm{mg}$.). This is contrasted with the findings in 11 female patients with rheumatoid arthritis who excreted an average of $12.8 \mathrm{mg}$. in 24 hours, with a range of from 3.5 to 21.6 (average for normal females $10 \mathrm{mg}$.). It is suggested that this point requires further investigation, since ankylosing spondylitis has such a predominating male incidence. E. F. Scowen.

Eosinophilia in Spondylitis Ankylopoietica. (Die Eosinophilie bei Spondylarthritis ankylopoietica rheumatica.) BöNI, A. (1947). Schweiz. med. Wschr., 77, 647.

Eosinophilia is often observed in the early stages of spondylitis ankylopoietica. The number of eosinophils varies between wide limits, as shown by specimen curves from 4 patients. Of 14 patients, 8 showed marked eosinophilia at the end of their first course of treatment, while in 6 cases the count was normal. The erythrocyte sedimentation rate curve shows deviations similar to, but not parallel with, those of the eosinophil count. The appearance of a constant eosinophilia usually heralds the onset of subjective and objective improvement in the patient's condition, even though the sedimentation rate may remain high. In the chronic stage of the disease the appearance of eosinophilia may again foreshadow improvement in the condition, although the latter may be preceded by temporary exacerbation of the disease process. S. S. B. Gilder.

Spondylarthritis Ankylopoietica. (Aspects actuels de la spondylarthrite ankylosante.) COSTE, F., Mouzon, M., and Boissière, H. (1947). Bull. Soc. méd. Hôp. Paris, 63, 493.

A review is made of 76 cases of spondylarthritis ankylopoietica; 1 patient was a female. This disease seems to have become commoner recently and, while the chief features remain unchanged, the peripheral joints appear to be more frequently involved ( $60 \%$ of cases); in more than a quarter the involvement was serious. Radiological examination showed most evident changes in the dorso-lumbar region. The erythrocyte sedimentation rate was raised in $85 \%$ of cases; in the majority of those in which the rate was normal the condition was not progressive. In only 2 cases was there a family history of spondylarthritis ankylopoietica, but in 12 others a member of the family had suffered from some form of rheumatism. The condition was seen in 14 patients who had been prisoners of war or who had been deported for forced labour; it is suggested that the rigorous conditions of life were aetiological factors.

T. G. Reah.

The Orthopaedic Treatment of Spondylarthritis Ankylopoietica. (De orthopaedische behandeling van spondyarthritis ankylopoietica.) KUIPERS, R. K. W. (1947). Ned. Tijdschr. Geneesk., 91, 851.

After a survey of the orthopaedic treatment of patients with ankylosing spondylitis already showing malformation of the spinal column, the author describes a corset designed to correct the malformations. Only when the corset fails to give the desired results should operative treatment be considered.

Spondylolisthesis. A Clinical and Radiological Study based on 70 Personal Cases. (Le spondylolisthesis. Étude clinique et radiologique d'après 70 observations personnelles.) SÈzE, S. DE, and DuRIEU, J. (1947). Sem. Hôp. Paris, 23, 1551.

Osteosclerotic Spondylopathy. (Le spondilopatie osteosclerotiche.) FERRERI, L. (1947). Radiologia, Roma, 7,495

Spondylitis in Brucellosis. (Espondilitis 'brucelósica.) Villafañe Lastra, de T., Faure, J. G., and Bergoglio, R. (1947). Medicina, B. Aires, 7, 308.

\section{(Miscellaneous)}

Surgical Treatment of Degenerative Arthritis of the Knee Joint. Haggart, G. E. (1947). New Engl. J. Med., 236, 971.

Conservative treatment in unilateral degenerative arthritis of the knee-joint was found to be so disappointing in the Lahey Clinic, Boston, that in 1940 a plan of surgical management was evolved in certain selected cases.

The operation requires that the patient's physical condition should be good, that he should be prepared to co-operate in tiresome and painful exercises in convalescence, and that he should be eager to return to normal activity.

This article is based on the results of operation on 35 patients whose average age was 57; of all the cases seen these few were suitable for operative procedures. Five patients with advanced degenerative arthritis had an arthrodesis. Postoperative fixation was obtained by a long leg plaster cast for 2 weeks; this was followed by a Stader unit for 6 to 8 weeks, and then a further long leg plaster cast which allowed the patient to walk and was maintained until radiographs showed that union was sufficient. Finally a long leg caliper was fitted until fusion was firm. The result was excellent in all cases.

A designed arthrotomy was carried out through a midline incision in 30 cases. Its object, as defined by Magnuson, was the complete removal of all mechanical irritants from the joint. The patella was either removed or lessened in size. Hypertrophied synovia and pads of fat were removed from the anterior compartment. Degenerated articular cartilage and exostoses were shaved away as well as the menisci, if involved. Exercises 
were started on the third day after operation and weightbearing was allowed within 2 weeks. It was found that a manipulation under " pentothal" anaesthesia within the third week in 3 out of 4 patients hastened recovery. Three patients did not co-operate and the results were poor. In 12 the results were excellent, but 8 patients still complained of aching pain with changes in the weather and 7 of mild discomfort on starting activity after rest. There was no change in later radiographs compared with those taken immediately after operation.

[To be successful conservative treatment must be initiated as early as possible in arthritis. It must be regular, prolonged, and vigorous, with the object of overcoming quadriceps wasting and securing a greater range of movement. The patient may have to be rested from weight-bearing for a period during treatment, and manipulation, with or without anaesthesia, may be an important part of treatment. Improvement is not, however, maintained in some patients in spite of this, and in certain selected cases from this group operative procedures such as are recommended in this article are indicated.]

W. E. Tucker.

Gonococcal Rheumatism Greatly improved by Aneurine Alone. (Rhumatisme gonococcique très amelioré par l'aneurine seule.) Coste, F., and BoIssière, $\mathrm{H}$. (1947). Rev. Rhum., 14, 177.

Articular Osteochondromatosis. (Osteocondromatosi articolare. Due casi.) MuSANTE, C. (1947). Infortun. Traumat. Lavoro., 13, 41.

Osteochondritis Dissecans. An Analysis of Forty-two Cases and a Review of the Literature. LAVNER, G. (1947). Amer. J. Roentgen., 57, 56.

\section{Gout}

Treatment of Gout by Vitamin $B_{1}$. (Le traitement de la goutte par la vitamine $B_{1}$.) Coste, F., Grigaut, A., and AuQuier, L. (1947). Sem. Hôp. Paris, 23, 312.

Of 32 patients with gout treated with aneurine, 18 derived marked benefit, since pain, stiffness, and objective signs disappeared; 10 improved slightly; 4 were not affected. The best results appeared to be obtained by combined oral and intravenous administration, the former preceding a combination of the two methods by several days. Oral dosage ranged from 20 to $30 \mathrm{mg}$. daily for 20 days; daily intravenous injections began with $10 \mathrm{mg}$., the dose being increased to $75 \mathrm{mg}$. and a course lasting for 8 to 11 days. No ill effects from the injections were observed, but 3 patients had exacerbations of their gout during treatment. The authors think aneurine should be used where colchicum treatment has failed.

\section{H. B. Gilder.}

An Approach to the Diagnosis and Treatment of Gout. Bartels, E. C. (1947). Bull. New Engl. med. Centre, 9, 86.

The authors emphasize that gout does not necessarily run hand in hand with wealth, obesity, and great eating and drinking; one-third of patients have never taken alcohol, and in less than half the initial attack starts in the great toe. Gout should be diagnosed from a history of attacks of acute arthritis in any of the joints of the extremities, lasting for a few days or weeks, and with complete remission. A cut-out shoe with no history of trauma, acute arthritis soon after operation, and nonspecific olecranon bursitis are all suggestive of gout.

Acute attacks are best treated by colchicine, $1 / 100 \mathrm{gr}$., every hour for six to eight hours, limiting the diet to carbohydrates. Intravenous glucose $(500 \mathrm{c.cm}$. of $20 \%$ solution) has been given daily in hospital with benefit. The interval treatment aims at lowering the uric acid in the blood by a diet low in purine and fat and high in carbohydrates, and by eliminating the uric acid by cinchophen or aspirin. Alcohol should be strictly forbidden as it may play a part in causing toxic manifestations from cinchophen. $\quad T$. G. C. Early.

Two Observations of Atypical Gout. (Deux observations de goutte atypique.) WEIL, M.P., and POILPRE, E. (1947). Rev. Rhum., 14, 174.

\section{Non-Articular Rheumatism}

Ruptured Intervertebral Disc and Sciatic Pain. BARR, J. S. (1947). J. Bone Jt. Surg., 29, 429.

Though the ruptured disc is universally recognized as a cause of sciatica, careful investigation is still necessary for accurate diagnosis. The negative explorations in some cases may be due to the fact that a prolapse is so far lateral that it can only be uncovered by facetectomy; the surgeon may be in doubt whether to do this or to carry out spinal fusion. Localized backache may be the only symptom of a protrusion so small as to escape notice both at myelography and at operations. There are, however, many other ligamentous and postural causes of backache, and many needless laminectomies have been performed on patients with ankylosing spondylitis.

Neurological examination fixes the level of the lesion in only half the cases, and the author states that most American surgeons use myelography as a routine. He prefers "pantopaque", which is aspirated after all the films have been taken, and in $90 \%$ of cases finds a correlation between radiographic and operative findings. Operation is reserved for intractable pain, for such gross features of root compression as paresis or sphincter disturbance, and for cases where conservative management has failed after 6 weeks. Though conservative treatment is varied, rest in bed during an acute attack with spine, hips, and knees slightly flexed is as good as any; the lower part of the back must be protected subsequently.

The author discusses the vexed question of whether spinal fusion should or should not be performed at the time of operation. In many cases it seems obvious that existing lumbar instability and the results of operative trauma call for the fusion of the adjacent vertebrae. On the other hand, some neurosurgeons maintain that fusion is rarely, if ever, indicated; this may be because they pay more attention to the relief of sciatica than to the subsequent condition of the back. Certainly, whenever a facetectomy has been done, fusion must be performed also or disabling symptoms may result. The author's view is that, since there is an even chance of chronic back symptoms developing after simple exploration, it is logical to carry out fusion in every case, provided the technique neither raises operative risks nor prolongs convalescence. Such a technique is available in the notched "clothes-pin" graft of Bosworth. This is taken from the ileum and wedged between the fourth lumbar and first sacral spinous processes, which are held widely apart in acute flexion so that the graft is firmly 
locked when the spine is again extended. A simple brace is all the postoperative immobilization needed, and patients are discharged from hospital in 4 weeks.

A questionary sent to 234 patients, 102 of whom had had a spinal fusion, revealed a modern but definite superiority of end-results in the fused cases. This was true not only as regards backache, stability, and capacity for exertion, but in respect of the root-irritation symptoms. The results in industrial accident cases were below average, and psychoneurotic complications were frequent; surgery should not, however, be withheld for these reasons. David Le Vay.

The Disc Factor in Low Back Pain with or without Sciatica. Love, J. G. (1947). J. Bone Jt. Surg., 29, 438.

The prolapsed disc is stated to be the commonest intraspinal cause of sciatic pain, and a conventional account is given of the clinical features. History and orthopaedic examination are usually conclusive. Neurological examination, though it must always be made, is not only not essential to the diagnosis but is of little value in locating the lesion. It may be confusing-for example, when a dermatome corresponding to a higher segment is involved through compression and ascending oedema of the cauda equina. The author advises routine myelography and personally favours introduction of oxygen or air as least irritant, though also least accurate. The simplest possible operative exposure is advocated, by unilateral reflection of the erector spinae, and excision of the ligamentum flavum, with removal of bone only where the interlaminar space is very narrow. The entire disc is not removed at the Mayo Clinic. A combined operation, in which the neurosurgeon removes the protrusion and the orthopaedic surgeon fuses the last two lumbar vertebrae to the sacrum, is desirable in many cases. However, the author does not consider that grafting should be a routine; not only may gross prolapse recur beneath a sound fusion but the extra stress imposed at the third space may cause a lesion at this level.

At the Mayo Clinic between 1939 and 1941 four neurosurgeons performed 1,217 operations with only 3 deaths; in $12 \%$ of patients the combined procedure was carried out. A follow-up of 987 showed that there was complete relief of pain in $53.7 \%$ and partial relief in $36.7 \%$ after simple removal of a protrusion. Nevertheless 35 to $40 \%$ still experienced aching in back or leg, and the same proportion were unable to continue their original occupation. The overall result was that $90.4 \%$ of patients had been relieved to some extent by operation, and $93 \%$ answered the frank question " Has the operation been worth while?" in the affirmative. Prolapse recurred in 47 at the original level, and many of these cases were resistant to any form of further treatment.

David Le Vay.

Pathological Studies of Intervertebral Discs. ECKERT, C., and DECKER, A. (1947). J. Bone Jt. Surg., 29, 447.

This is a report on the histology of the specimens of discs removed at laminectomy in 166 patients, compared with control material obtained at necropsy. The changes observed were not essentially different from the normal effects of ageing seen in the controls. These included nuclear prolapse into the cartilage plate with vascularization of the extension; scarring of nucleus and annulus; and granular degeneration of the nucleus with patchy calcification, presumably the sequel to desiccation. No relation seemed to exist between histology and clinical end-results.
An Analysis and Differentiation of Low-Back Pain in Relation to the Disc Factor. STEIndLer, A. (1947). J. Bone Jt. Surg., 29, 455.

The author believes that the intact intervertebral disc has few sensory fibres and gives rise to little pain. It is one of the first structures to undergo senescent change. Simple thinning and collapse cause relaxation of the ligamentous connexions of the adjacent vertebrae and re-alignment of the intervertebral joints. Thus, recurrent lumbo-sacral strain may result from new stresses on ligaments and muscles before any actual herniation has occurred; at the same time, reactive hypertrophic arthritis may produce root symptoms by encroaching on intervertebral foramina. Herniation itself is a continuous process, and an originally mobile protrusion capable of spontaneous reduction may become fixed and adherent to nerve roots. Recurrent exacerbations are probably due to gross oedema of the fragment.

In diagnosis, neurological signs are a sufficient and desirable proof of the existence of a disc prolapse. In their absence it is advisable to seek a trigger-point and to see if procaine injection abolishes the referred pain; should this be the case, no disc lesion exists.

Laminectomy is indicated once the diagnosis is certain; fusion is essential whenever backache is a prominent feature of the history, and should preferably be performed as a routine. However sparing of bone the laminectomy may be simple removal of the prolapse cannot relieve lumbo-sacral instability which exists before the operation. The Bosworth " clothes-pin " method of fusion is a good one. David Le Vay.

Lumbago, Sciatica, and Endocrinology: Heterotopic Endometriosis. (Lombo-sciatalgie et endocrinologie. Contribution à l'étude des endométriomes hétérotopiques.) Dagnelie, J. (1947). Ann. Endocrinol., 8, 26.

A woman of $\mathbf{3 2}$ gave a long history of pain in the back and along the distribution of the sciatic nerves; the pain had disappeared during a pregnancy and reappeared 6 months afterwards. It was worse during the follicular phase of the menstrual cycle and had been greatly aggravated by an injection of follicular hormone. A thorough investigation revealed two extremely tender nodules in the pelvis. Pressure on one of these provoked pain along the back of the left leg. A 9-months' course of testosterone (10 mg. four times a month) was given with complete relief from pain after the first injection. When the injections were temporarily stopped the pain returned within 3 months; further injections caused it to disappear again. The pelvic nodules have become smaller and less tender. It is assumed that the cause of pain was pressure on nerves by nodules of heterotopic endometrium.

$$
\text { S. S. B. Gilder. }
$$

Low Back Pain Associated with Varices of the Epidural Veins Simulating Herniation of the Nucleus Pulposus. EPSTEIN, B. S. (1947). Amer. J. Roentgen., 57, 736.

Three cases of low back pain associated with epidural varices are reported. In 2 the diagnosis of prolapse of an intervertebral disc was made on clinical and myelographic evidence, in the third on clinical evidence alone. All 3 patients had a history of trauma preceding the onset of the low backache. The pain, which in 2 of the cases was made worse by coughing and sneezing, radiated down the leg on the affected side. Sometimes the pain was prolonged and severe. Changes in the ankle-jerk 
and knee-jerk were present in 2 cases, and in 1 there was atrophy of the leg and thigh. The total protein content of the spinal fluid was raised in 2 of the patients and was close to the upper limit of normal in the third case. Radiographs showed no abnormality. Myelography with "pantopaque" revealed defects at the level of the sacro-iliac disc in 2 cases, and these were interpreted as due to prolapse of the disc.

The paper discusses the anatomy of the epidural veins and the differentiation of the myelographic appearances in dilated epidural veins and in varicosities of the pial veins. Whereas in cases of dilated epidural veins the myelographic picture is indistinguishable from that of a prolapsed disc, dilated pial veins are enveloped by the pantopaque, and channel-like radiotranslucent shadows are produced where the opaque oil is displaced by the dilated veins.

A. Orley.

Laminectomy and Foraminotomy with Chip Fusion. Operative Treatment for the Relief of Low-back Pain and Sciatic Pain Associated with Spondylolisthesis. BriggS, H., and KeATS, S. (1947). J. Bone Jt. Surg., 29, 328.

The authors draw attention to the fact that the symptoms of backache and crural pain in patients with spondylolisthesis are not always completely relieved by spinal fusion. They have tried to devise an operative procedure which will not only stabilize the spine but also afford lasting relief of pain. They believe it essential to explore the intervertebral disc in all cases; in those with radiating pain exploration of the nerve roots is necessary as well.

R. Furlong.

Choice of the Best Operative Method in Sciatica due to Disk Lesions, on the Basis of Late Results. (Le choix de la meillure méthode opératoire dans les sciatiques d'origine discale d'après l'etude des rèsultats éloignés.) Petit-Dutaillis, D., and Pertuiset, B. (1947). Mém. Acad. Chir., Paris, 73, 396.

During the last five years the authors have modified their technique for the treatment of sciatica due to disc lesions, because of the fairly frequent occurrence of homolateral lumbar pain or contralateral sciatica after simple removal of the disc. They now decide at operation whether or not a prolapsed disc is responsible for symptoms. If it is not, bilateral rhizotomy is undertaken of L5 and S1. The results in 17 cases were: perfect, 2; very good, 6 (slight persistent coccygeal pain or vasomotor disturbance in the leg); good, 7 (some persistent lumbar pain, paraesthesiae, or vasomotor disturbances in the legs); failure, 1 ; recurrence, 1.

For sciatica due to prolapsed disc they advise removal of the disc together with rhizotomy of L 5 or S1 (unilateral or bilateral), but not both of these roots; in 28 patients so treated there were 12 perfect results, 8 very good results, and 5 results marred by residual pain after prolonged effort or by contralateral sciatica; the results were mediocre in 3 patients, there being persistent lumbar pain or paraesthesiae. In a total of 250 disc operations prolapse has only recurred 7 times; prolapse of another disc has occurred 3 times.

After rhizotomy of both $\mathrm{L} 5$ and $\mathrm{S} 1$ paraesthesiae and even trophic lesions may be disturbing, though not really severe. Anaesthesia extends over the lower half or twothirds of the antero-lateral and postero-lateral aspects of the leg, the retro-malleolar fossa as far as the heel tendon, the lateral half of the dorsum of the foot and the lateral third of the sole, and the dorsal and plantar aspects of the three lateral toes. Sometimes the anaesthetic area includes the first and second toes, and it may extend proximally over the postero-lateral aspect of the knee or even as far as the gluteal fold.

Cutting the first sacral root causes anaesthesia or hypoaesthesia along the lateral border of the foot and adjacent parts of dorsum and sole, the two lateral toes, the lateral retro-malleolar sulcus, and the lowest part of the postero-lateral aspect of the leg. Proximally the anaesthesia sometimes extends over the upper part of the leg, the knee, or even the thigh, in their lateral aspects. Fifth lumbar rhizotomy usually produces a vertical band of anaesthesia on the antero-lateral aspect of the leg, often extending to the plantar and dorsal aspects of the great toe or the first two or three toes. A certain number of rhizotomies are followed by paraesthesiae, vasomotor effects, and either hyperhidrosis or anhidrosis. Trophic disturbances are exceptional, but were observed in one case of rhizotomy of both L5 and S1. Rhizotomy of a single root, even if bilateral, is tolerated; rhizotomy of both L5 and S1 may be followed by effects which, though not serious, are none the less appreciable, and the operation should be resorted to only if a cure cannot be obtained by other means. In sciatica due to prolapsed disc it is reserved for the treatment of recurrence of pain without obvious recurrence of prolapse.

Some of the recurrences in this series seemed to be due to persistence of "lipiodol" within the nerve roots; as far as possible lipiodol examination is dispensed with in diagnosis.

Ian Aird.

Operative Results in Intervertebral Disks. GRANT, F. C. (1946). Ann. Surg., 124, 1066.

The author points to the paucity of postoperative follow-up reports in cases of lumbar disc protrusion and quotes a number of published series. He points out that the, pain has two components, pain in the back being due to pressure upon or rupture of the posterior vertebral ligaments, and pain in the leg to protrusion of the disc against the adjacent nerve roots. Maybe the back pain points to a structural disability of the back which later gives rise to the protrusion. The author's own contribution deals with the results of surgical removal of an abdominal disc in 200 cases with a followup period of 6.5 to 1.5 years (average 3 years). A questionary was sent out to 275 patients; 200 replied and 150 reported in person. In this series $63 \%$ were completely relieved of all pain, $29 \%$ were improved, and $8 \%$ were unimproved or worse. The results were not affected by the occupation of the patient, being apparently the same in those doing heavy manual work as in those of sedentary occupation. The degree of the protrusion had a bearing on the results, these being best with the ruptured disc, less good where the annulus protrudes without rupture, and least good in cases of the so-called " hidden" disc.

The author also analyses two other groups of cases. Of 29 cases in which no disc protrusion was found at operation the results were approximately the same as those which followed removal of " hidden" discs. Of 44 cases in which the diagnosis of a disc protrusion was made and operation was not performed, $23 \%$ underwent spontaneous cure and $41 \%$ were considerably improved. He concludes by urging caution upon those who are prepared to operate when the diagnosis of a lumbar disc protrusion has been made without assessing the severity of the patient's pain or considering its duration and the number of previous attacks. 
The "Last-straw" Factor in Low Back Disability. With Summary of 100 Cases Examined and Evaluated by the Medical Advisory Board of the Industrial Commission of Arizona, 1934-1943. WATKINS, W. W. (1947). Radiology, 48, 20.

This report is based on 100 cases examined and evaluated by the Medical Advisory Board of the Industrial Commission of Arizona in 1934-43. The author points out the difficulty in assessing the compensation for injuries, alleged or real, sustained by workers whose radiographs immediately after an accident show evidence of developmental anomalies or pathological changes. He considers that, while such conditions as rheumatoid arthritis produce clinical signs before radiographic changes, osteo-arthritic changes are usually symptomless long after they are radiologically evident. A workman with either of these conditions who sustains an injury may well be disabled for a long time, and serial radiographs show progressive development of the pathological processes. The assessment of compensation for this "last straw" damage is much more difficult than is suggested by the awards of the Medical Advisory Board. J. F. Brailsford.

Fibrositis. Mowbray, J. (1947). J. med. Ass. Eire, 21, 8.

The main theme of this article is that fibrositis, the commonest form of the rheumatic conditions, has become amenable to treatment owing to recent and brilliant researches upon its aetiology. Stockman in 1920 described the histology of a typical nodule as first an exudation of fluid with lymphocytes, and next becoming organized by invasion with fibroblasts and blood vessels which were finally almost obliterated by the appearance of dense connective tissue; but it was left to Sir Thomas Lewis and later Kellgren to show that pain originating in muscular foci yielded to injections of procaine, clearing up by this method many cases which had remained stubborn to physical methods. When procaine injections into an area remove the pain, tenderness, and stiffness, several factors are probably at work-the bulk of the fluid breaks down adhesions, and the immediate relief of spasm and pain on movement encourages the patient and thereby helps to abolish " habit-spasm".

The diagnosis is helped by noticing whether active and passive movements are each painful in the same direction, in which case the structure at fault is probably a ligament or other inert body; or whether active movement is painful in one direction, and passive movement in another, when the site must be in muscle or tendon. Fibrositis is found not only in muscle, tendon, and bursa, but can involve the capsules of joints, both primarily or secondary to rheumatoid and osteo-arthritis - the former showing itself as a painful, tender, but not swollen joint accompanied by muscular wasting with no radiological changes and a normal sedimentation rate.

As for focal sepsis, eradication may well improve the patient's general condition but is unlikely to cure the local fibrositis.

The importance of developing sensitive fingers which will feel the slight spasm of muscle is emphasized.

\section{T. E. C. Early.}

The "Costoclavicular Syndrome". Telford, E. D., and Mottershead, S. (1947). Brit. med. J., 1, 325.

The causes of symptoms of pressure on the neurovascular bundle in the region of the thoracic inlet are discussed in relation to: (1) operation findings in 120 cases; (2) investigation of the effects of posture on the radial pulse in 120 healthy medical students; and (3) dissection of 30 bodies. Of the operation cases, 14 showed extensive arterial thrombosis, and in these there was a well-developed cervical rib. In no case, however, was any abnormality found in the artery in the region of the rib. Indeed, in only 2 cases did the thrombosis extend above the level of the lower border of the pectoralis major. Of 104 uncomplicated cases, 69 showed some degree of cervical rib; in 12 there was a strong taut band arising from the tip of a small cervical rib, and passing downwards and forwards in the anterior border of the scalenus medius; 8 showed a condition in which the insertion of the scalenus medius was carried forward further than normal.

Diminution or arrest of the radial pulse can be produced by certain positions of the shoulder girdle. This is due to compression of the axillary artery below the clavicle and not, as is frequently stated, of the subclavian artery. Adduction of the arm against resistance was most effective in interfering with the radial pulse, producing complete arrest in $66 \%$ of cases.

In 12 out of 18 dissections made with the arm by the side of the body a sharp S-turn was found in the axillary artery at the level of the second rib. At this point the artery was embraced in a scissors-like manner by the heads of the median nerve, which were seen to constrict the vessel on depression of the shoulder. This constriction was demonstrated directly in one case at operation. It is suggested that obliteration of the pulse in forcible adduction of the arm may be due to compression of the axillary artery by the pectoralis minor and subscapularis. In no case did dissection afford any support for the belief that symptoms may be due to compression of the brachial plexus between the clavicle and the first rib when the shoulder is depressed. Clavicular pressure may occur in retraction and abduction of the shoulder; but usually the symptoms are due to kinking of the brachial plexus over a cervical rib, a band, the scalenus medius, or an abnormal first rib when the shoulder is depressed. Vascular disturbances are due to causes distal to the clavicle and have nothing to do with the costo-clavicular syndrome.

A. Barer.

The Supraspinatus Syndrome. ARMSTRONG, J. R. (1947). Lancet, 1, 94.

The supraspinatus syndrome is a frequent cause of shoulder pain, often overlooked. The lesion may be a small tear in, or a tendinitis of, the supraspinatus tendon, or a subacromial bursitis, produced by injury of the abducted upper limb; symptoms are caused by impingement of the affected tendon and/or bursa against the acromion process in the middle range of abduction of the shoulder joint.

In 31 patients submitted to operation the pathological macroscopical findings were: (a) inflamed thickened bursal wall with a red thickened underlying tendon (15 patients); (b) calcified deposits in a thickened bursa and tendon (6); (c) tears of the supra spinatus tendon (5); (d) bursitis, difficult to distinguish from bursitis with tendinitis (5). Most patients gave a history of injury, the injury being followed, immediately in the patients with a tear of the tendon and later (12 to 24 hours) in those with a contused tendon and bursa, by pain referred to the insertion of the deltoid muscle; a painful arc on abduction of the shoulder-joint between 60 and $120^{\circ}$; a reversed scapulo-humeral rhythm; and tenderness localized to the subacromial bursa. Later there might be periarticular adhesions due to lack of use of the shoulder 
producing true limitation of movement. The syndrome may be confused with: (1) complete rupture of the supraspinatus tendon, but in the latter condition there is loss of ability to abduct the shoulder-joint; (2) " frozen shoulder ", where there is generalized stiffness of the joint with much pain on forced movement; (3) tuberculous arthritis of the shoulder-joint, which should be distinguished by muscle spasm and wasting, by pain at the end of the joint movements, and by the $x$-ray appearances. Fibrositis and neurosis are frequently diagnosed where the supraspinatus syndrome exists.

Of 89 patients suffering from supraspinatus syndrome, 58 recovered with conservative treatment-rest of the upper limb in a sling rather than in an abduction splint for 1 week followed by active shoulder exercises. Infiltration of the tender area with local analgesic, radiant heat, and short-wave diathermy were used, but the author considers that improvement obtained by these measures was temporary. In the remaining 31 patients conservative measures failed; accordingly removal of the acromion through an antero-posterior "sabre cut type" incision over the region of the acromio-clavicular joint was performed. The whole acromion, including the articular surface of the process at the acromio-clavicular joint, needs to be removed, otherwise there is danger of incomplete relief of symptoms due to removal of insufficient bone. This happened in 5 of the first 9 patients submitted to operation; 3 were again operated on with complete relief of symptoms. Postoperatively, the limb is rested in a sling by the side of the body for 1 week; this is followed by active movements. In about 3 to 4 weeks, according to the author, movements are full. [This statement seems optimistic.]

The author admits that he is unable at the onset of treatment to determine which patients will require excision of the acromion; in his experience, however, the operation is indicated where: (a) supraspinatus syndrome "causing material disability" is associated with calcified deposits in the tendon; and (b) a supraspinatus syndrome with disability is not cured by conservative treatment in 2 to 3 months. The operation should not be performed where there is true limitation of movement of the shoulder-joint due to periarticular adhesions; these should be dealt with first by physiotherapy, and if necessary by manipulation.

[This article would have been of greater value if the author had followed up his cases and had been able to present end results after, say, 3 or 5 years.] David Trevor.

Causalgia. A Report on 32 Cases. PASRICH, H. R. (1946). Indian med. Gaz., 9, 337.

This article describes 32 cases of causalgia in Indian troops. Mitchell's original criteria have been followed, and a pain classified as.causalgic only if it was: (a) in the region of a peripheral nerve subjected to damage; (b) spontaneous; (c) continuous; (d) liable to exacerbation; and (e) burning. Causalgic pain followed injury within 7 to 10 days; pain occurring more than 3 weeks later was looked upon with suspicion. The incidence was $2 \%$ in peripheral nerve injuries with a preponderance in Gurkhas; it is thought that, because in Gurkhas there is a tendency to keloid formation, they are especially liable to intraneural fibrosis. Support for this view is adduced from the fact that, after the general use of penicillin in the forward areas, infection of the wounds and subsequent scarring was reduced and the incidence of causalgia fell. Of the 19 cases of median nerve causalgia, 4 showed no signs, motor or sensory, of damage to any of the nerves of the limb, and 7 showed complete anaesthesia in the area affected by the causalgia. Ischaemia due to concomitant damage to the blood vessels was negligible. The pain always began in the same area of the limb - that is, in the lateral half of the palm of the hand and in the sole of the foot. The conclusion is that the focus of irritation lies in the intraneural fibrosis affecting the central fibres of the nerves, and impulses from this focus set up changes in the spinal or thalamic centres. Before treatment was begun an injection of procaine was given into the sympathetic ganglionated cord. Four cases yielded to repeated injections, but periarterial sympathectomy was performed in 3 cases, and section of the ganglionated cord in 21 . All the sympathectomies gave dramatic results except in a man who lost his pain but had hyperaesthesia for 3 months afterwards.

H. T. Simmons.

Rheumatic and Syphilitic Juxta-articular Nodes. (Rheumatische en luetische knobbels bij de gewrichten.) DiJKSTRA, O. H. (1947). Ned. Tijdschr. Geneesk., 91, 1299.

A biopsy of subcutaneous nodules in the region of the elbow-joint was made in two cases of chronic rheumatism. The histological picture was one of connective tissue containing areas of degeneration sharply demarcated by a zone of connective-tissue cells. Exudate, principally of lymphocytes, was scanty. The same type of nodule was found in a third case without evidence of rheumatism.

Comparison is made with the nodules found in yaws and syphilis, on the basis of four specimens. These nodules, which like the rheumatic nodules may attain the size of a walnut, are not so strictly juxta-articular as the former and contain more exudate, usually with plasma cells present. An arrangement of concentric layers can often be distinguished. Photomicrographs are reproduced. H. B. Gilder.

Sciatica and the Intervertebral Disc. JACK, E. A. (1947). Rheumatism, 3, 122.

Sciatica and “Blocked" Septic Foci. (Ciática y foco séptico bloqueado.) FERRERo, R. G. A. (1947). Rev. argent. Rheumatol., 12, 127.

Sciatica, with particular Reference to its Causes and Treatment. RoGERS, L. (1947). Post Grad. med. J., 23, 517 .

Surgical Treatment in Cases of Chronic Rheumatism. (Áké sú možnosti chirurgickej terapie chronického reumatizum.) CERVEŇAŇSKÝ, J. (1947). Slov. Lek., 9, 195.

Myalgia and Fascialgia in Sciatica. (Myalgie en fascialgie bij ischias.) PEERAER, D. (1947). Belg. Tijdschr. Geneesk., 4, 66.

The Importance of Diet in Chronic Rheumatism. Mules, H. L. (1947). Med. Pr., 128, 345.

Chronic Rheumatism in the Hand and Neurotrophic Rheumatism of the Upper Limb. (Rhumatismes chroniques de la main et rhumatisme neurotrophique du membre superieur.) RAVAult, P. P., GuINET, P., BerTHIER, L., EMERY, —, and CARRIER, P. (1947). J. Méd. Lyon, 657, 363. 


\section{General Articles}

Rheumatism. O'Reilly, T. J. (1947). J. med. Ass. Eire, 21, 2.

Although the history of rheumatic diseases is long, it was not until Heberden in 1805 described the nodes which bear his name that any useful knowledge began to accumulate; Heberden pointed out that these pea-like tumours near the joints of the fingers " have certainly nothing in common with gout, for they are found in many patients who have no experience of that disease ".

The social changes which occurred in Germany at the end of the nineteenth century, and in England in 1911, with social insurance, free medical treatment, and certification to control the treatment, showed up the extent of the illness due to rheumatism. Much organized treatment and research was carried out-the latter yielding few results until recently in the case of fibrositis. The importance of the latter is emphasized by the figures of the first 5,000 patients attending the Dublin rheumatism clinic - of whom $70 \%$ suffered from fibrositis, $18.5 \%$ from osteo-arthritis, $10 \%$ from rheumatoid arthritis, $1 \%$ from ankylosing spondylitis, and $0.5 \%$ from gout. There is no doubt that many cases show a marked hereditary factor; climate seems to play some part, in that two peak periods, one in the spring and one in the autumn are often noted, both bearing some relationship to two virus diseases-the common cold and influenza.

Most treatment takes the form of physiotherapy, either heat or massage. The one great discovery, that of gold injections in the treatment of rheumatoid arthritis, was made in 1928 . Other methods, such as manipulation of joints, are finding their place. But rheumatism clinics, where treatment can best be carried on, are only feasible in densely populated countries with large cities.

T. E. C. Early.

Arthritis in the Mediterranean Theatre of Operations. I. Incidence of Joint Disease-Clinical Description of Rheumatoid Arthritis. SHORT, C. L. (1947). New Engl. J. Med., 236, 383.

Strictly surgical conditions, such as the immediate effects of wounds on joints, bones, muscles, etc., have been excluded from this paper; but fibrositis (under all its names) has been included because it is often confused with arthritis, as has "psychogenic" arthritis. Rheumatic fever is considered only in the differential diagnosis.

The importance of arthritic diseases as causes of manpower loss is shown in several tables. Only three other classes of patient (neuropsychiatric, skin, and gastrointestinal) have an incidence greater than the arthritic amongst those admitted to the seventy-third station hospital from August, 1943, to April, 1945. Percentage of total admissions was 1.8 for arthritis. An estimate of the man-days lost through hospitalization for arthritis from January, 1943, to May, 1945, came to 275,000 .

At the Army and Navy General Hospital at Hot Springs, Arkansas, the incidence of various types of arthritis based on 2,000 cases was as follows: rheumatoid, $34.3 \%$; psychogenic $18.8 \%$; fibrositis $13.6 \%$; hypertrophic arthritis, $12.4 \%$; gonorrhoeal, $1.4 \%$; miscellaneous causes, $19.5 \%$.

Patients with joint symptoms but no objective changes were found most frequently $(40 \%)$ in the Mediterranean theatre; rheumatoid and hypertrophic arthritis followed with $25 \%$ each; and specific infective arthritis numbered less than $10 \%$.

The average age for rheumatoid arthritis was 39 years 9 months, higher than that for either arthralgia (34/9) or hypertrophic arthritis $(38 / 10)$. Over half these patients gave a history of previous attacks, mostly without complete remission. Generalized symptoms such as tiredness and loss of weight were common $(87 \%)$, sometimes before the onset of arthritis; vasomotor instability such as cold feet, sweating, and motor weakness were also present. Articular swelling was almost invariable, though occasionally a diagnosis was made with only pain and tenderness in symmetrical joints. Laboratory tests were not helpful: the sedimentation rate was raised in only about half the cases, the white cell count was variable, and $x$-ray examination of the joints was usually negative. Most of the "specific" forms of treatment were left untried; only fever therapy was given a chance in a few cases. The results were not impressive, nor was much success gained by removing even obvious "septic foci". Rest in bed, relief of pain and physical therapy were the chief treatments given.

Atypical rheumatoid arthritis comprised some 18\% of cases; it often followed an infection (viz. of the upper respiratory tract), and affected several joints in asymmetrical fashion. Chemotherapy was tried, usually without effect.

Rheumatoid spondylitis was found in $20 \%$ of patients with rheumatoid arthritis in the Mediterranean theatre. Many men who undoubtedly had this disease fought through a campaign, and one parachutist made a number of jumps.

T. E. C. Early.

Arthritis in the Mediterranean Theater of Operations. II. Clinical Description of Hypertrophic Arthritis, Arthralgia and Psychogenic Rheumatism. SHORT, C. L. (1947). New. Eng. J. Med., 236, 429.

Arthritis in the Mediterranean Theater of Operations. III. Clinical Description of Infectious and Other Types of Arthritis. SHORT, C. L. (1947). New Eng. J. Med., 236, 468 .

The author continues his review of joint disease in the Mediterranean area.

A Coefficient of Severity in Rheumatic Diseases. (Un coefficient de gravité des affections rheumatismales.) MicheZ, J. (1947). Arch. Rhum., 7, 66.

The author has devised a chart, reproduced in the article, in which marks can be assigned to the several features of the disease which he thinks relevant to an assessment of its gravity; the sum of these marks is the " coefficient of gravity", which in his opinion is of service in judging the progress of a patient and in assessing the value of a particular treatment. The features to which marks are to be assigned are grouped under three heads: (1) the extent of the disorder: in this the several joints of the body are listed, with columns for marks according to the degree of pain, stiffness, decalcification, or synovitis, and deformity; (2) the activity of the disease process: here the criteria are E.S.R., pyrexia, and anaemia; (3) the degree of disability. The marks to be assigned to the various objective signs, in their several degrees, and to the other features of the case are indicated. Kenneth Stone. 
Final Consideration on the Development of a Group of 721 Rheumatic Children. (Consideraciones finales sobre la evolucion de un grupo de 721 ninos reumaticos.) Barbato, D. (1947). Arch. Pediat. Urug., 18, 116.

A statistic review of 721 cases of rheumatic disease in childhood seen during 4 years is given. The cases are grouped into the following 6 classes according to their clinical condition when first registered (numbers in brackets): (1) acute articular rheumatism without cardiac involvement (139); (2) rheumatism with cardiac involvement but no insufficiency (429); (3) cases suspected of rheumatism (muscular pains, joint pains, etc.) but without cardiac signs (84); (4) rheumatism with cardiac insufficiency (43); (5) chorea without heart signs (16); (6) chorea with heart signs (10). Classification on any grounds but clinical was not considered feasible.

Cases are divided into (a) dead (69), (b) survived, and kept under review for at least 4 years (359). In group (a) the causes of death were: cause unrelated to the heart condition, 6; cause unknown, 4; rheumatic heart disease, 59 . Of these 59,28 were originally registered in class $4 ; 29$ in class 2 , and 2 in class $1: 28$ were girls, 31 boys. In 39 the illness began with the classic type of acute articular rheumatism. The greatest time between the beginning of the illness and death was 10 years, and between the beginning of cardiac insufficiency and death 6 years. In 41 the final clinical lesions did not involve the pericardium. At death the youngest was 5 , the oldest 21 years, and the majority of deaths occurred at 10 years old.

In group (b) progress was noted by the change in the heart condition. Of 54 cases in class 1, 45 remained the same and 9 grew worse (i.e. cardiac signs appeared). In class 2 (237), 137 remained the same, 65 improved, and 35 grew worse. In class $3(46), 29$ remained the same and 17 grew worse. In class 4 (9) all improved. In class 5 (8), 4 developed heart lesions. In class $6(5)$, 4 remained the same and 1 improved.

The authors do not claim to have been so thorough as some authors, but they feel that their statistics confirm that their classification was useful. One of their objects was to have a basis on which to launch their campaign for a social attack on rheumatic disease.

\section{J. G. Jamieson.}

Significance of Function in the Genesis and Development of Experimentally Induced Polyarthritis and Carditis. (Die Bedeutung der Funktion für Entstehung und Entwicklung experimentell hervorgerufener Polyarthritiden und Karditiden.) INGELMARK, B. E. (1947). Acta med. Scand., 128, 203.

Pathological changes in joints and adjacent tissues, and in the myocardium, were found in rabbits previously injected intravenously with a suspension of enterococci isolated from the faeces in a case of polyarthritis. A freshly prepared suspension $(2 \mathrm{ml}$.) from growth on ascites-agar was injected into an ear vein; this was repeated after 48 hours and again after 96 hours, each animal thus receiving three injections. The animal was killed 5 weeks later.

The observations were carefully controlled; all experimental and control animals lived under identical conditions, apart from "training". The following groups were studied: (A) animals . submitted to training (compelled to undergo a measured amount of running exercise daily, by being placed in a cabinet whose floor was an endless moving belt) both before and after inoculation; (B) animals submitted to training for a period before inoculation only; (C) animals trained only after the last inoculation; (D) animals not trained at all. When the results were examined, training appeared to have exerted a remarkable influence.

The pathological changes found were thickening of the synovial membrane; foci of lymphocytes and plasma cells in synovial membrane, capsule, and periarticular tissues; enlargement of synovial villi with round-cell infiltration hyperaemia; synovial exudation; and cartilage destruction. There was no neutrophil exudation. In all control animals except one, round-cell infiltration of the myocardium was found, but the number of cell infiltrations per unit volume was found to be smaller than in the experimentally infected animals. No changes were found in the endocardium or epicardium. More joints were affected and the morbid changes were far more pronounced in groups $A$ and $B$ than in $C$ and $D$. There was little difference between animals of groups $\dot{C}$ and $D$; some animals of group A showed rather more marked changes than any of group B. Control animals submitted to the same training showed no joint changes.

It would follow that training before inoculation is responsible for a more marked pathological reaction. Though it would appear that training is the cause of a lowering of resistance to experimental infection of the heart and joint tissues, the author is careful to point out that the conclusion cannot be held as true for all tissues and all animals, tissue resistance being affected by a very large number of factors. It is in harmony with the clinical observation that acute and chronic rheumatism affect joints in active use earlier and more frequently than those used less.

Kenneth Stone.

Temperature Equalization for the Relief of Pain. An Experimental Study of the Relation of Thermal Gradients to Pain. Wells, H. S. (1947). Arch. phys. Med., 28, 135.

Although heat increases blood flow, there is little evidence that deficient blood flow has anything to do with those types of pain that respond well to heat. The present observations are based on studies carried out on a normal subject (the author), but confirmation of important findings has been obtained from other subjects.

A metal "serrefine" (syringe-type artery clamp), when applied to a finger web, causes moderate pain, which is lessened or even abolished if hand and clamp are warmed in air and water. The same results are obtained when the circulation in the arm is stopped by the inflation of a sphygmomanometer cuff, so that the analgesic effect of heat is not in this case due to an increase in blood flow to the injured area. Warming the hand alone failed to relieve the pain if the clamped tissues were kept cool by dipping the projecting metal in water at the initial skin temperature of the hand. Similarly, the warming of larger areas of the body failed to relieve the pain. If the hand is maintained at its original temperature, warming the end of the clamp by dipping it in water at $34^{\circ}$ to $37^{\circ} \mathrm{C}$. relieves the pain, but it recurs if the clamp and clamped tissues are heated above $37^{\circ}$ or $38^{\circ} \mathrm{C}$., with an increase in its intensity if the warming is carried above $45^{\circ} \mathrm{C}$. Above that point tissue is injured and pain occurs as a result.

Further experiments are described.

Roentgen Therapy in Arthritis, Bursitis, and Allied Conditions. P POHLE, E. A., and MORTON, J. A. (1947). Radiology, 49, 19.

This paper is part of a symposium on rheumatic diseases. The great majority of 100 consecutive patients 
considered were suffering from osteo-arthritis. There was an additional group of 69 cases of subdeltoid bursitis. $X$ rays were used in treatment, with a half-value layer of either $1.05 \mathrm{~mm}$. copper or $2.4 \mathrm{~mm}$. copper. The spinal areas were treated through an $8 \times 20 \mathrm{~cm}$. port (1 to 3 areas) and the smaller joints through $10 \times 10$ or $15 \times 15 \mathrm{~cm}$. ports. The spinal areas received three irradiations of $150 \mathrm{r}$ (in air) on successive days, or three of $200 \mathrm{r}$ on alternate days.

The authors conclude that the response to treatment is in all probability due to the non-specific analgesic effect. In the osteo-arthritis group, satisfactory relief was obtained in about $75 \%$ of cases. The aged and the severity of the disease are not reliable guides in prognosis. The possible psychological effect of treatment is not denied. The response to treatment of bursitis was good, with satisfactory relief in $84 \%$ of cases, in over half of which there was calcification before treatment. Especially good results were obtained in acute cases; in some of those with calcification the calcium deposit disappeared. A. G. C. Taylor.

Plantar Neuromas, Morton's Toe. Bickel, W. H., and DoCkERTY, M. B. (1947). Surg. Gynec. Obstet., 84, 111.

In the painful affliction of the foot which now goes by his name, Morton succeeded in obtaining cures by excision of the fourth metatarsophalangeal joint and the surrounding tissues, but he did not identify any precise pathological process. In 1893 Hoadley cured a case by resecting a small neuroma of the branch of the lateral plantar nerve to the fourth toe. The significance of this finding was not appreciated until 1940, when Betts again drew attention to this condition and the results of excision. The authors review their experience of 18 patients, 16 women and 2 men aged from 25 to 67 years; most were overweight. The pain was usually felt beneath the heads of the third and fourth metatarsals and the contiguous sides of the corresponding digits, though occasionally it spread to the neighbouring digits. Pain was sometimes paroxysmal at night, and paraesthesiae in the affected toes were common. In 16 cases there was a localized tender spot over the site of the neuroma, and firm pressure here with a blunt instrument gave rise to typical radiating pain and paraesthesiae. Operation was carried out on each of these patients, conservative treatment having failed.

Patients suffering from this type of pain are usually women and commonly wear small, high-heeled shoes. The 2 men in this series wore ill-fitting shoes. Trauma and weight-bearing appear to be prime causes, but the authors consider that the anatomy of the plantar and digital nerves is also partly responsible for the pathogenesis.

D. W. C. Northfield.

Reiter's Disease. Harkness, A. H. (1947). Brit. med. J., 103, 72.

The author defines Reiter's disease as a clinical syndrome characterized by non-gonococcal urethritis, bilateral conjunctivitis, arthritis (usually polyarticular), occasionally balanitis and keratodermia blennorrhagica. The condition, always venereal, has a relatively long incubation, runs a protracted course, and may recur after long periods of remission. Urethritis is usually of the Waelsch type, though some cases may have a profuse purulent abacterial discharge with pain and frequency. In the author's series conjunctivitis appeared 2 to 16 days after the discharge started, and polyarticular arthritis
1 to 6 days later. Keratodermia blennorrhagica occurred subsequently in $50 \%$ of cases. This syndrome has also been described in association with gonococcal urethritis, though in these cases there is often a mixed primary infection, and in staphylococcal septicaemia. However, confusion is most liable to arise from its more frequently reported association with bacillary dysentery. The author considers that Reiter's original case was of dysenteric origin, and notes that Feissinger and Leroy, in a study of an outbreak of dysentery in 1916, observed the same clinical syndrome in 4 of their cases. The arthritis in cases of this type is more commonly met with during convalescence than during the acute stage, and is more frequently monoarticular. It is suggested that cases be differentiated into those of dysenteric and of venereal origin, and that the term " Reiter's disease ", or " dysenteric arthritis" be reserved for the former; the latter should be described as " non-gonococcal polyarthritis" or " the non-gonococcal syndrome".

A. Henderson Begg.

Treatment of Reiter's Syndrome by Gold Salts. WiLlcox, R. R., Findlay, G. M., and Henderson-BegG, A. (1947). Brit. med. J., 1, 483.

This is a description of 2 cases of Reiter's syndrome in which gold therapy appeared to expedite recovery.

Milkman's Syndrome with Fissuring of the Skeleton. (Syndrome de Milkman et fissurations spontanées du squelette.) MONDOR, H., and LeGER, L. (1947). J. Chir., Paris. 63, 85.

This is a careful study of Milkman's syndrome based on the 80 cases published so far by some 30 authors, and on 8 new observations. The syndrome is identified by the $x$-ray appearance of the bones. There are multiple, often symmetrical, transverse bands of translucency in many of the long and flat bones of patients who come for examination because of "rheumatic" pain (worse on movement) and general weakness.

L. Michaelis.

\section{Osteomalacia with Looser's Nodes (Milkman's Syndrome) due to a Raised Resistance to Vitamin D Acquired about the Age of 15 Years. MCCANCE, R. A. (1947).} Quart.J. Med., 16, 33.

The original of this most important article on Milkman's syndrome should be consulted, since no précis can be adequate.

Penicillin Treatment of Rheumatism. (Pénicillinothérapie des rhumatismes.) Coste, F., and GALMICHE, P. (1947). Bull. Soc. méd. Hôp. Paris, 63, 503.

The authors record the results of treatment with penicillin of 163 cases of rheumatism, which include 84 cases previously reported (Sem. Hôp. Paris, Nov. 7, 1946).

Sudeck's Syndrome in Trivial Injuries. (Zur Frage des Sudeckschen Syndroms bei Bagatellverletzungen.) Nicole, R. (1947). Radiol. clin., Basel, 26, 93.

The author believes that wherever Sudeck's atrophy follows a trivial injury the triviality of the latter ought to be doubted, a thorough radiographic examination made, and treatment adjusted accordingly. L. Michaelis. 